\title{
A LITERATURA E AS POLÍTICAS PÚBLICAS PARA FORMAÇÃO DE LEITORES NO BRASIL: O CASO DO PNBE
}

\author{
Maria Thaize dos Ramos Lira, Universidade Federal Rural de Pernambuco (UFRPE), \\ thaize_ramosjp@hotmail.com \\ Taline dos Ramos Lira, Universidade Federal de Campina Grande (UFCG), \\ talineramoslira@hotmail.com \\ Vicentina Maria Ramires, Universidade Federal Rural de Pernambuco (UFRPE), \\ vicentinaramires@terra.com.br
}

\begin{abstract}
RESUMO
Entendemos que a leitura exerce papel fundamental na vida das pessoas que vivem em uma sociedade letrada, e que a democratização da leitura emana de políticas públicas, o presente trabalho tem como objetivo discutir o Programa Nacional Biblioteca da Escola (PNBE), no sentido de compreender sua apropriação pelas escolas públicas. Especificamente, buscamos caracterizar o Programa dentro das políticas públicas de leitura, discutindo a formação do leitor de modo a perceber suas contribuições e impasses para as escolas. A pesquisa se desenvolve a partir de análise de documentos e revisão bibliográfica, adotando como metodologia a leitura dos documentos oficiais referentes ao PNBE disponibilizados nos sites do Ministério da Educação (MEC). A fundamentação teórica respalda-se principalmente nos estudos de Roger Chartier (2001), Magda Soares (2006), Regina Zilberman (2009) entre outros autores que discutem leitura, políticas públicas de leitura e formação de leitores. Dessa forma, refletir sobre o PNBE, entendido como uma política pública de leitura proposta pelo governo federal, pode se configurar numa maneira de se problematizar a relação leitura literária e escola, principalmente, quando se foca a biblioteca e a formação de leitores.
\end{abstract}

PALAVRAS-CHAVE: Literatura; leitura; PNBE; Formação de leitores.

THE LITERATURE AND PUBLIC POLICIES OF TRAINING OF READERS IN BRAZIL: THE CASE OF PNBE

\begin{abstract}
Summary we believe that reading plays a fundamental role in the lives of people living in a society that is literate, and that the democratization of reading emanates from public policies, this paper aims to discuss the National Program The School Library (Pnbe), in order to understand its appropriation by public schools. Specifically, we characterize the program within the public policies of reading, discussing the formation of the reader to understand their contributions and impasses for the schools. The research develops from document review and literature review, adopting as methodology the reading of official documents relating to the PNBE made available on the websites of the Ministry of Education (MEC). He theoretical supports mainly in studies by Roger Chartier (2001), Magda Soares (2006), Regina Zilberman (2009) among other authors that discuss reading, public policies and training of readers. Thus, reflecting on the PNBE, understood as a public reading policy proposed by
\end{abstract}


the federal government, can be configured in a way to problematize the relation between literary reading and school, especially when focusing the library and the formation of readers.

KEYWORDS: Literature; reading; PNBE; Training of readers.

\section{LA LITERATURA Y LAS POLÍTICAS PÚBLICAS DE FORMACIÓN DE LECTORES EN BRASIL: EL CASO DEL PNBE}

\section{RESUMEN}

Creemos que la lectura juega un papel fundamental en la vida de las personas que viven en una sociedad que está alfabetizada, y que la democratización de la lectura emana de las políticas públicas, el objetivo de este trabajo es discutir el programa nacional de la Biblioteca Escolar (Pnbe), a fin de comprender su apropiación por parte de las escuelas públicas. Específicamente, caracterizamos el programa dentro de las políticas públicas de lectura, discutir la formación del lector para entender sus contribuciones y callejones sin salida en las escuelas. La investigación se desarrolla a partir de la revisión de documentos y revisión de la literatura, adoptando como metodología la lectura de documentos oficiales relacionados con el PNBE disponibles en los sitios web del Ministerio de Educación (MEC). La base teórica apoya principalmente en estudios por Roger Chartier (2001), Magda Soares (2006), Regina Zilberman (2009) entre otros autores que discutir la lectura, las políticas públicas y la formación de lectores. De esta forma, reflexionar sobre el PNBE, entendido como una política pública de lectura propuesta por el gobierno federal, puede configurarse de una manera de problematizar la relación lectura literaria y escuela, principalmente, cuando se enfoca la biblioteca y la formación de lectores.

PALABRAS CLAVE: Literatura; Lectura; PNBE; Formación de lectores.

\section{INTRODUÇÃO}

Partilhamos da ideia que é por meio da leitura literária que o aluno desenvolve as capacidades de pensar, compreender, imaginar e ultrapassar o texto, posto que, o que caracteriza o texto como literário é a sua polissemia, suas brechas, suas lacunas a serem preenchidas pelo leitor. Desta forma, este trabalho pretende analisar e discutir as apropriações dos livros literários disponibilizados pelo Programa Nacional Biblioteca na Escola (PNBE) para a formação de alunos leitores. Na atual conjuntura social, a leitura é valorizada como uma ferramenta essencial para que o homem possa compreender o mundo a sua volta de maneira crítica, e a literatura desempenha um papel primordial.

De acordo com as premissas de Rojo (2004), as pesquisas realizadas nas últimas décadas apontam que grande parte da população, mesmo tendo acesso à escola, nem sempre tem se formado leitora. Informações do Indicador do Analfabetismo Funcional (INAF) de 2011 denotam que $57 \%$ da população adulta que ingressa no ensino médio permanecem no 
nível básico de alfabetismo, ou seja, não é considerada alfabetizada. Ressaltamos que a expectativa é de que todos aqueles que ingressam nesse nível de escolaridade estejam na fase de escolaridade plena, para que, assim, possam fazer um uso eficaz da leitura.

Não se trata de atribuir à literatura como redentora da pátria. Muito menos colocar a responsabilidade pelos déficits e dificuldades educacionais. De acordo com as premissas de Soares (2006), o que se anseia é sinalizar o uso proveitoso da literatura na escola, a fim de promover a aproximação do aluno à leitura. Corroboramos com a assertiva de que a leitura literária possibilita interpretações e compreensões ancoradas em perspectivas sociais e culturais que ampliam diferentes temáticas e contextos sociais.

Em seus estudos acerca do uso da literatura na escola, Brito (2012), aponta que o trabalho com a literatura na escola estimula o senso crítico e novas habilidades ao aluno que vão além do campo do imediatismo. De acordo com o autor, mais do que desenvolver o gosto e o prazer pela leitura, o trabalho com a literatura impulsiona a própria construção de conhecimento. Por conseguinte, o texto literário, incorporado na formação do leitor, o capacitará a analisar e avaliar conceitos, interpretações e a conjuntura atual através das histórias escritas em outros períodos e assim, poder criticar as suas próprias compreensões e as dos outros.

Ao se aludir de forma específica sobre a leitura e literatura, Magda Soares (2006), assegura que o desenvolvimento e o gosto pela leitura tem sido comprometido pela inadequada escolarização da literatura. De acordo com as premissas da autora, a determinação de leituras e livros, atividades de leitura e a realização de avaliação das leituras são algumas das circunstâncias que, ainda nos dias de hoje, estão presentes nas práticas escolares, e que, na maioria das vezes, não possibilita a leitura na escola em termos qualitativos. O uso inadequado da literatura faz com que:

Distinguimos entre uma escolarização adequada e uma escolarização inadequada da literatura: adequada seria aquela escolarização que conduzisse eficazmente às práticas de leitura literária que ocorrem no contexto social e às atitudes e valores próprios do ideal do leitor que se quer formar, inadequada é aquela escolarização que deturpa, falsifica, distorce a literatura, afastando, e não aproximando, o aluno das práticas de leitura literário, desenvolvendo nele resistência ou aversão ao livro e ao ler (SOARES, 2006, p. 47).

Soares assegura que a escolarização da literatura é um processo inevitável, visto que é a função básica da escola instituir os saberes constituídos através das didatização e da 
pedagogização de conhecimentos e normas escolares. Posto que, é preciso que se conheça ou se descubra práticas de leitura mais apropriadas à escolarização da literatura por se saiba ou se descubra práticas de leitura mais adequadas à escolarização da literatura a partir da consideração do meio social dos leitores.

Os estudos de Ziberman (2009) elencam rumos importantes para a constituição do leitor literário, quando discute a função da família e da escola neste contexto. Segundo afirma a autora, é papel da família trazer livros para casa e coloca-los disponíveis às crianças. Por outro aspecto, à escola caberia estimular situações individuais de leitura, como as que a criança sente quando utiliza espaços de forma espontânea e livre de pressões, um ambiente que proporcione o prazer de quando ele brinca. Seguindo essa postura, Carvalho (2005, p. 67) afirma que o prazer pela leitura se dá de variadas formas, "e pode ser apreendido na família, na escola ou em outros ambientes distintos".

Ao pensarmos acerca da biblioteca escolas e os profissionais que nela estão envolvido, notamos que muitas escolas do Brasil nem apresentam espaços físicos adequados para à leitura e, ainda, que seja muito difícil encontrar profissionais com formação adequada para trabalhar nas bibliotecas. Esta é uma situação que tem provocado algumas dificuldades no que se refere à própria formação de leitores. Refletir e discutir a leitura literária na escola e a sua vinculação com as políticas públicas de leitura permite pensar no mundo instigante de aproximação ou distanciamento entre aluno, leitura e literatura.

De tal modo, podemos perceber que é preciso investir e qualificar todos os sujeitos envolvidos no processo de leitura para que possam contribuir com a formação de leitores críticos. Nessa lógica, investigar acerca do PNBE, na qualidade de política pública implementada pelo governo federal, pode se configurar como uma alternativa para problematizar a relação literária na escola e de forma especial, quando se concentra na biblioteca escolar e a formação de leitores. Partindo dessa discussão, planejamos contribuir para os estudos acerca do processo de formação de alunos leitores.

O PROGRAMA NACIONAL BIBLIOTECA DA ESCOLA E A FORMAÇÃO DE ALUNOS LEITORES

O Programa Nacional Biblioteca da Escola (PNBE) foi instituído pela Portaria Ministerial n 584, de 28 de abril de 1997, é gerido pela Secretaria de Educação Básica do 
Ministério da Educação - SEB / MEC e executado pelo Fundo Nacional de Desenvolvimento da Educação - FNDE, ambos dependentes ao Ministério da Educação - MEC. O PNBE busca atingir seus objetivos por meio da distribuição anual de acervos de livros de apoio ao professor.

Por volta de 2008, passou a comtemplar todos os níveis de escolaridade, sendo que em 2009, estabeleceu a distribuição em anos e séries. Nos anos pares, o programa atende as séries iniciais do Ensino Fundamental ( $1^{\circ}$ ao $5^{\circ}$ ano), Educação Infantil e a Educação de Jovens e Adultos (EJA) e, nos anos ímpares, atende aos anos finais do Ensino Fundamental $\left(6^{\circ}\right.$ ao $9^{\circ}$ ano) e Ensino Médio.

No decorrer de sua história, o PNPE veio se transformando e tentando se moldar à realidade e necessidades educacionais. Estudos referentes ao programa contribuíram para que este se desenvolvesse na tentativa de expandir o atendimento e, sobretudo, alcançar sua ambição de promover a cultura e instigar a leitura de alunos e professores por meio da distribuição de acervos às escolas públicas de todo o Brasil.

De acordo com as mudanças de currículo ocasionadas pelas novas transformações econômicas, sociais e culturais no cenário mundial, pelas novas teorias da aprendizagem, teorias pós-críticas e pelas novas tecnologias que alcançaram um crescimento gigante nas últimas décadas, aos poucos, foi se percebendo mudanças nos modelos de ensino, os conteúdos, até então tidos como tradicionais, tem passado por especulações. No interior desses novos modelos, a literatura vivenciou algumas transformações no ensino fundamental e médio mesmo que, não sejam totalmente benéficas para o processo de formação do aluno leitor.

Uma percepção tradicional de ensino de literatura pode ser reconstruída de Gustav Lanson, no século XIX, que tem como cerne uma definição culta da leitura:

(...) a explicação do texto (...) forma o julgamento e o espírito de análise e permite descobrir o patrimônio literário francês, principalmente quando acompanhada de uma exposição, do professor, das noções de história literária. O texto literário é sacralizado. A explicação do texto tem dois objetivos. O primeiro de ordem moral: apreendido sob a forma de admiração, de modelos de conduta e de ética. O segundo hermenêutico: trata-se, pela análise da composição e do estilo, de elucidar expressões, e de atingir o "pensamento" do autor, a significação verdadeira do texto (BAUDELOT et al., 1999, p. 162). 
De acordo com Resende (2011), podemos argumentar que esse modelo, trazido da França, foi aos poucos sendo alterado de acordo com o gosto do freguês,

a explicação do texto deu lugar à adoção de supostos estilemas de época que explicam a obra, perdendo esta sua individualidade para integrar-se a um painel anódino gravado no manual didático; quanto ao lado moral, os modelos de conduta e de ética variam muito com o tempo - antes, o Bem, o Belo, o Verdadeiro - hoje, antinômicos da Violência, das Drogas, da Sexualidade Promíscua, são temas "transversais" da escola e são buscados preferencialmente em narrativas contemporâneas direcionadas sobretudo a um público juvenil - portanto os "clássicos" deixaram de cumprir há muito essa função (RESENDE, 2011, p. 2).

A mesma autora afirma que está em extinção o professor que seja capaz de fazer uma análise adequada do texto, sendo o livro didático considerado o mártir das explicações da obra literária e de inseri-la na história. Segundo Geraldi, cabe ao professor, "a escolha do material didático que usará na sala de aula. Mas qual a sua função depois disto? Uma boa metáfora é compará-lo a um capataz de fábrica: sua função é controlar o tempo de contato do aprendiz com o material previamente selecionado" (GERALDI apud RESENDE, 2011, p. 2).

Agregado à esse fator, vemos que o livro literário já não tem mais nos dias de hoje, a hegemonia como um espaço de conhecimento. Ele está ao lado de outras linguagens, com a função de informar e transmitir conhecimento. Essas outras linguagens, leia-se de modo especial, as narrativas eletrônicas e digitais, desempenham um papel muito atrativo na vida das crianças e jovens que acabam por desde cedo, a usar essas narrativas como uma forma de distração e entretenimento, deixando a sociabilidade de lado. Concordando com as ideias de Roger Chartier (2001), nunca vimos uma mudança de suporte como a que acontece agora com os meios eletrônicos e digitais, e que vem interferindo de forma tão intensa na forma de percepção e conhecimento dos indivíduos.

Neste cenário, não basta equipar as escolas com um acervo enorme de material, isso por si só não irá garantir a efetivação da leitura. Já sabemos que o livro sozinho, fechado ou guardado, não irá atingir nenhum objetivo. Por este fato, a apropriação e o uso do material do PNBE são importantes, posto que podem contribuir para a formação de leitores dentro e fora do ambiente escolar. Esta ideia de apropriação deve ser pautada pelo "caminho mais imediato para conhecer as apropriações dos alunos, é o da confidência dos leitores a respeito de seus modos de ler e dos sentidos que se descobre nos textos" (CHARTIER, 2001, p. 12). 
De acordo com Chartier (2001), apropriar-se é fazer algo com o que se recebe no sentido da pluralidade de usos, das múltiplas interpretações da vastidão de textos, posto que a hermenêutica, como uma arte de interpretar. Apropriar incide na ideia daquilo que os indivíduos fazem com o que recebem, sendo pois uma forma de invenção, de criação ou de produção desde o momento em que se conquistam textos ou objetos recebidos.

$\mathrm{Na}$ maioria das vezes, a prática docente, pauta-se ao desenvolvimento da leitura no processo de ensino-aprendizagem numa concepção mais mecânica, voltada para a decodificação e ampliação do conhecimento puramente de conteúdos curriculares, [...] quando a leitura é considerada um objeto de conhecimento, seu tratamento na escola não é tão amplo como seria de se desejar, pois em muitas ocasiões a instrução explicita, limita-se ao domínio das habilidades de decodificação (SOLÉ, 1998, p. 36).

Por outro lado, há também a perspectiva de leitura como processo de compreensão abrangente, cuja dinâmica envolve componentes sensoriais, emocionais, intelectuais, fisiológicos, neurológicos, tanto culturais, econômicos e políticos. Kleiman (1985) vem enfatizar que:

Quanto à concepção de leitura, consideramos esta uma prática social que remete a outros textos e outras leituras. Ao lermos um texto, qualquer texto, colocamos em ação todo o nosso sistema de valores, crenças e atitudes que refletem o grupo social em que se deu nossa socialização primária, isto é, o grupo social em fomos criados (KLEIMAN, 1985, p. 10).

Neste contexto, ocorrem duas concepções distintas que, de um lado gera um aprendizado mecânico e de outro, um aprendizado significativo. Assim, a segunda concepção gera um mecanismo que compete a leitura a função de relacionar social e cultural. A leitura, nesta concepção, não é um elemento adquirido somente no contexto escolar, mas pelas relações com a família, destacando que o ato de ler não está submetido somente as relações com a escola. Para Martins (1985, p. 10), "a leitura do mundo precede sempre a leitura da palavra e a leitura desta implica a continuidade daquela”.

Desfaz-se a concepção antiga como a criação das primeiras escolas em que, ao adentar a instituição escolar, o aluno não traz consigo nenhuma informação importante para a construção da leitura já que esta estaria limitada a decodificação de textos oriundos dos livros didáticos e para a compreensão de textos informativos ou científicos. 
Assim, o indivíduo começa a ler, efetivamente, ao passo que inicia a sua relação com o meio e com os demais indivíduos, através da interação de linguagem social. Há uma relação entre o ler e os sentidos, as emoções e a razão, convencionando-se em três níveis: sensorial, o emocional e o racional. Seria então, necessário, considerar a leitura como um processo de compreensão e expressões formais e simbólicas. Na leitura há uma compreessão sem a necessidade de racionalização, justificativas, apenas pelo fato de impressionar os sentidos. A leitura emocional, por outro lado, emerge da empatia sendo, pois, uma maneira do indivíduo interagir com o objeto lifo emocionalmente. Por fim, a leitura racional consiste numa visão do objeto lido, acrescentando à leitura racional à sensorial e a emocional.

Por muito tempo, a escola concebeu a leitura como um meio de ascensão social ou tão somente como uma orientação para que os indivíduos se situem no contexto social. Deixou-se de lado a necessidade de despertar o prazer pela leitura, o gosto por uma prática que pode ultrapassar a decodificação através da construção de ideias e contextos dos próprios alunos, como seres pensantes.

Saber ler é uma exigência da sociedade contemporânea e uma condição essencial para o exercício pleno da cidadania. Segundo Jouve (2002, p.17), a leitura é, "antes de tudo, um ato concreto, observável que recorre às faculdades definidas do ser humano". Há o consenso entre vários teóricos e educadores de que a leitura desempenha papel primordial na construção de conhecimentos e para o exercício da cidadania. É por meio dela que se pode expandir o entendimento do mundo, adquirir informações e permitir que os sujeitos tenham autonomia e reflexão crítica.

Assim, fica evidente que a criança aprende a gostar de ler antes mesmo de dominar os signos linguísticos e compreender a leitura em si. Esta começa a compreender as histórias que lhes são contadas, o contexto sociocultural no qual está inserida. A função do educador, neste contexto, não seria a de ensinar, mas a de instigar os indivíduos a despertar o gosto pela leitura no sentido de que, através desta é que se dá a efetivação do conhecimento. Na sala de aula, a leitura se torna o sinônimo de condição para se conseguir a aprovação naquele ano, e assim, acaba por se perder a sua função de relacionar o homem ao mundo em que ele vive, com o prazer de compreender a si mesmo e aos outros. Esta necessidade é claramente declarada por Cavalcanti (2002).

Ler sempre representou uma das ligações mais significativas do ser humano com o mundo. Lendo reflete-se e presentifica-se na história. O homem, 
permanentemente, realizou uma leitura do mundo. Em paredes de cavernas ou em aparelhos de computação, lá está ele reproduzindo seu "estar-nomundo" e reconhecendo-se como capaz de representação. Certamente, ler é engajamento existencial. Quando dizemos ler, nos referimos a todas as formas de leitura. Lendo, nos tornamos mais humanos e sensíveis (CAVALCANTI, 2002, p. 130).

Esta relação texto-leitor-mundo, principalmente, no ambiente escolar, deve ser observada e considerada para que seja compreendida em sua função mais importante. Por outro lado, não é exatamente o que se presencia.

Enfim, o processo de leitura, dada a sua amplitude e importância requer um olhar especial dos educadores no sentido de promover atividades envolventes que levem os educandos a serem verdadeiros leitores. É necessário, segundo Zilberman (1985, p. 87) “que o texto funcione como instrumento de integração do sujeito ao meio, através da aceitação dos padrões sociais, conduza-o a refletir sobre a realidade posicionando-se criticamente diante da mesma".

Um aspecto do chamado "fracasso escolar" gerado pela falta de interesse pela leitura consiste na pobreza de recursos ambientais motivadores para tal atividade. Verifica-se escolas em que os livros literários são instrumentos distantes dos alunos, cabendo a estes somente o contato com textos informativos, pois, para alguns educadores, literatura é diversão e a escola não é lugar para tal.

Kleiman (1985, p. 15), ressalta que [... ] a leitura tem no cotidiano do brasileiro, a pobreza no seu ambiente de letramento, ou ainda, a própria formação precária de um grande número de profissionais da escrita que não são leitores, tendo, no entanto, que ensinar a ler e a gostar de ler." Para formar leitores, devemos ter paixão pela leitura. Torna-se quase impossível tornar alguém apaixonado por algo que o próprio incentivador não tem prazer, não conhece, não pratica.

Um outro problema a ser encarado é o fato de que as leituras não são acessíveis aos seus leitores do ponto de vista do nível de compressão e maturidade. A escola preocupa-se, tão somente com níveis de desenvolvimento aferindo metas quantitativas e transcrições de teorias, deixando de lado a necessidade do desenvolvimento cognitivo.

Neste aspecto Kleiman (1985, p. 16) destaca que "ninguém gosta de fazer aquilo que é difícil demais, nem aquilo do qual não consegue extrair o sentido. Essa é uma boa caracterização da tarefa de ler em sala de aula: para uma grande maioria dos alunos ela é difícil demais, justamente porque ela não faz sentido". 


\section{ALGUMAS CONSIDERAÇÕES}

A escola e a sala de aula devem funcionar como espaços promotores do diálogo entre texto e leitor, de modo que as leituras realizadas possam ser compartilhadas e estabelecidas como parte da realidade do aluno. Quanto mais se enfatiza cobranças e mensurações no que tange à leitura e à produção escrita do aluno, mais ele se afasta e se distancia do efetivo gosto pelas mesmas. Nosso papel, enquanto educadores e pesquisadores consistem em estimular o aluno a desenvolver o hábito da leitura.

Entendendo a leitura como fundamental para o exercício da cidadania, várias ações elaboradas pelos órgãos oficiais surgem com o desígnio de melhorar os índices de desempenho da leitura no Brasil. Diante dessa visão, pensamos que a falta de interesse dos alunos pela escrita e leitura pode se dá pelo fato de que a escola, em algum momento, pode desenvolver práticas desmotivadoras, cujo espaço da leitura é reduzido à instrução.

Adentra ao cenário, o professor como um mediador entre o aluno e o mundo da leitura, da necessidade do mesmo possuir uma formação adequada para lidar com o mundo da ficção, do imaginário, da leitura. Sendo assim, o trabalho com a leitura precisa ser um processo ativo e contínuo na escola e também que possibilite que o aluno interaja com a literatura. Ao propiciar este contato, a escola harmoniza a leitura significativa que vai além da mera decodificação.

\section{REFERÊNCIAS}

CARVALHO, M. Alfabetizar e letrar: um diálogo entre teoria e prática. Petrópolis, RJ: Editora Vozes, 2005.

CHARTIER, Roger. (Org.) Práticas da Leitura. 2 ed. São Paulo: Estação Liberdade, 2001.

JOUVE, Vicent. A leitura. São Paulo: Editora UNESP, 2002.

KLEIMAN, A. B. (org.) Os significados do letramento: uma nova perspectiva sobre a prática social da escrita. Campinas, Mercado das Letras, 1995.

"Programa de educação de jovens e adultos" In: Educação e Pesquisa Revista da Faculdade de Educação da USP. São Paulo, v. 27, n.2, p.267 - 281. 
REZENDE, N. L. de. O ideal de formação pela literatura em conflito com as práticas de leitura contemporâneas. In: SANTINI, J. (Org.). Literatura, crítica, leitura. Uberlândia: EDUFU, 2011. p. 275-293.

SOLÉ, Isabel. Estratégias de leitura. Porto Alegre: Editora Artmed, 1998.

ZILBERMAN, Regina. A literatura infantil na escola. 5. ed. rev. ampl. São Paulo: Global, 1985 .

MARTINS, Maria Helena. O que é leitura? 19 ed. São Paulo. Brasiliense, 1994. 